\title{
WEB AUTOMATION FOR POWER MECH SYSTEMS
}

\author{
Ravi Ramu Mallannavar ${ }^{1}$ and Mrutyunjaya.S.Emmi ${ }^{2}$
}

\begin{abstract}
The requirements for developing develops web site's in Word press platform for professional machines manufacturing company and we are responsible for developing the corresponding and huge dynamics of web design, considering the web site's orientation. In this website we will display the projects, service's posts and also the similar modules. A client can visit the website and view all the details about the company. Then client will send requirement quotation through mail, After that the system will generate the billing details and generate quotation report, payment reports and send to the client. Once a client receives the quotation report and payment reports then client do the payment manually. Finally order the products.

Keywords - Admin, Client, Estimation quotation, Payment, Report.
\end{abstract}

\section{INTRODUCTION}

Word Press is a content management system and also generates the dynamic pages in PHP that is mainly used for developing website. A various sources show that Word Press is used in many websites. The WP-admin (Dashboard) is the first page when you logs into the admin area. The main reason of Word Press is the rich system of plug-in and themes that have grown up around the Word Press platform, enabled by a flexible and ever-increasing group of expansion points built into the platform. This has enabled a large system of open-source and plug-in to develop, In this our project Power Mech Systems we are using a The 7 theme for the designing the website on it.

Word press enables to website's owner for upgrade page contents to operate a blogs page through interface. Word press framework will at online website creation devices at PHP. It is not complicated and powerful creating site Content management system (CMS) in existing these days. This in day includes the theme, module make at very attractions pages, posts in websites.

Any machine's manufacturing company can a well equipped in engineer and designs, search and developmental center, installation coaching or team. This gathers sectors are advanced processing equipment's and constructing development groups. We introduce ourselves as one of the upcoming manufacturers of complete range of specialized custom built Material Handling Systems and Equipment's. These Equipment's and Systems are useful for dust and critical material handling for complete spectrum of core sector process industry such as Cement, Steel, Chemicals, Thermal Power, Sponge Iron, etc. in India \& Abroad.

In this we making the website for company and it will be mainly uses for clients. And it can using word press platform for attractive web design and development make on attractive website and typically interaction between company and clients. In this, Power Mech Systems will mainly made quality and assembling a wide ranges on machineries work as like constructions (civil), mechanicals so on. Furthermore, they will works with partners together for machine producing organization. The client visits website for requiring the company product details and service details. Hence client will gets requiring details then client will send requirement quotation include product name, product quantity and service. The company receives client's requirement quotation through mail and Power Mech Systems will make a billing process. First admin will checks the available product items then he will generates the estimation quotation of client requirement in this estimation quotation admin calculates the product item cost of

${ }^{1}$ Department of Master of Computer Applications Gogte Institute of Technology, Belagavi, Karnataka, India

${ }^{2}$ Faculty, Department of Master of Computer Applications Gogte Institute of Technology, Belagavi, Karnataka, India 
how much quantity will want and also shows the how much amount client given and remaining amount and also generates the duplicate estimation quotation purpose of company. Next the admin generates the estimation quotation report like client wise and also generates the client payment and client payment report like date wise and admin will send these estimation quotation report and payment report to the client mail then admin generates the all clients estimation quotation report purpose of the company. When clients receives the estimation quotation report then make payment manually to Power Mech Systems.

This website is very useful for client because of easily getting the all the information in a click and getting reports for order the product and payment. In this site payment is done by online it is done by manually.

Word Press is a content management system (CMS) and also generates the dynamic pages in PHP that is mainly used for developing website. A various sources show that Word Press is used in many websites.

\section{LITERATURE SURVEY}

A. Existing System-

In Existing as usually uses the basic HTML, CSS for making the static web pages describing the format of document, which allows to views on computer. HTML documents are displaying on browser, finding about regarding any details will very difficult, of the clients goes to check information in manually.

- It is only to displaying the WebPages but didn't any update.

- In this static WebPages are very unique to update the data.

- Coders who can search across the networks and different variety data.

- Need a huge of working staffs and extra attention to maintain all the data.

- In an working of the clients billing process as manually.

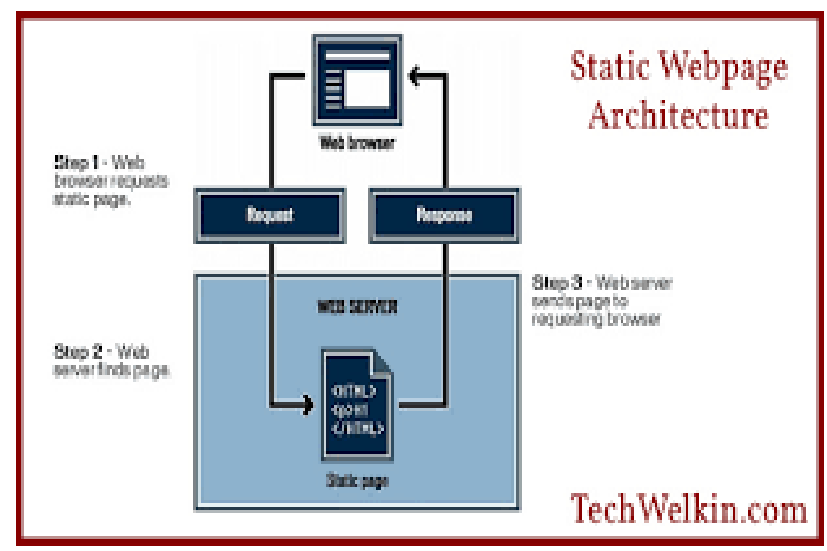

Fig 1. Static webpage

\section{B. Proposed System-}

In proposed system, attractive dynamic pages are designed using Word press for making website. It is quite easy to understand and also provides user friendly interface.

- In this will minimize the manual work and managing time. 
- Only that functional work will going here.

- Minimum time needs of the POWER MECH SYSTEMS Company processing.

- You will get the details about the company by online.

- In an make a billing process and generate client estimate requirement and payment reports.

- Database will provide the authorized for the POWER MECH SYSTEMS information.

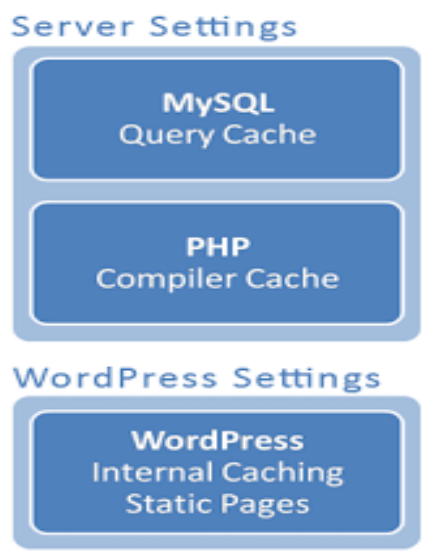

Fig 2 Word Press Server Architecture

\section{IMPLEMENTATION}

\section{1) Admin:}

Admin is office users will be handling \& authenticate this website and billing processes only he will be manages a Power Mech Systems database. He will be maintains website of like modify the data in and delete the data in website to make interface for clients.

\section{2) Client}

Client can take services to Power Mech Systems and client is view the displayed information in Power Mech Systems website like the company production, manufacturing, services details. And also checks how this company wills works and which variety of products manufacture in their company and then sent requirement quotation through mail to Power Mech Systems Company and will settle the payment manually.

\section{3) Estimation Quotation:}

Estimation quotation module is the estimate whoever client will sent quotation can be estimate the requirements of client product item and how much amount it will be cost and also check given amount in this field.

\section{4) Payment:}

It is used to make the generate payment details and payment reports of the client requirement quotation. 


\section{IV.CONCLUSION}

Power Mech Systems is for all sectors developed website helps customers to take the information of various types of company products details, service details, by just sending the requirement quotation with specific model. This is very helpful the customers to visit website and also user friendly to it. Clients will be easily gets the product and services billing quotation and payment report quickly.

This website is efficient, very easily use, and also good interaction, which reducing the interaction distance b/w the PMS of users. This system will be flexibility only this much for amendments or implementations that can arrive in future panning.

\section{FUTURE ENHANCEMENT}

1. The Power Mech Systems will make the online purchase equipments' of products.

2. Member login interface can be included.

3. Online payment facility can be implemented.

4. We can monitor the sales and other transaction graphically on respective dashboard.

5. Developing the material handling and lifting equipments.

\section{REFERENCES}

[1]. Luke Welling: PHP and MySQL Web Development, 2001.

[2]. Larry Ullman : PHP for the World Wide Web, 2001.

[3]. Brad Williams, David Damstra, Hal Stern : Professional Word Press.

[4]. Jesse Friedman: Web Designers Guide to Word Press,2008.

[5]. Byrne, Jim. 60 hot to touch Accessible Web Design tips - the tips no web developer can live without!, Jim Byrne, 2006.

Referrence Links

[1]. https://www.w3schools.com/php/default.asp

[2]. https://www.w3schools.com/sq1/default.asp

[3]. http://www.wpbeginner.com/category/wp-tutorials

[4]. https://www.codeschool.com/learn/php

[5]. https://premium.wpmudev.org/blog/mysql-databases/ 